ORIGINAL ARTICLE

\title{
A Comparative Study of Polysomnography Findings in Children with Prader-Willi Syndrome and Non-syndromic Children
}

\author{
KR Bharath K Reddy ${ }^{1}$, Susha Nair ${ }^{2}$
}

\begin{abstract}
Aim and objective: There are insufficient data in India on sleep issues in children with Prader-Willi syndrome (PWS). This study was undertaken to describe the prevalence of sleep problems, polysomnography findings, and treatment of sleep issues in children with PWS.

Research questions: (1) To determine the prevalence of sleep problems in children with PWS and (2) to compare the polysomnography (PSG) findings in children with PWS and non-syndromic children with obstructive sleep apnea (OSA).

Materials and methods: Retrospective data of children who underwent polysomnography for the diagnosis of sleep problems were extracted and divided into two groups. The first group consisted of 20 children with PWS, and the second group consisted of 22 non-syndromic children with OSA. History was analyzed using a parent-administered sleep questionnaire, and a level one polysomnography was performed in all study subjects. Results: No significant difference was noted in the sleep history between the two groups. The OSA prevalence of the PWS group was $100 \%$. The OAHI, OAHI (REM), baseline oxygen saturation, and time of saturation below $90 \%$ were significantly affected in the PWS group compared to the non-syndromic group. Thirteen children with PWS who had moderate-to-severe OSA were started on CPAP and were clinically better, of which nine of them who underwent a follow-up sleep study showed resolution of OSA on PSG.

Conclusion: Children with PWS suffer from moderate-to-severe OSA. OSA with significant hypoxemia is seen in REM sleep in PWS children, necessitating the need for early intervention with noninvasive ventilation. All children with PWS must undergo PSG due to possible underestimation of sleep issues on parental history.

Clinical significance: The degree of obstruction could be underestimated on parental history in children with PWS, thus necessitating the need for a sleep study in all children with PWS, especially prior to hGH therapy.

Keywords: Noninvasive ventilation, Obstructed sleep apnea, Polysomnography, Prader-Willi syndrome, Sleep study.

Indian Journal of Sleep Medicine (2020): 10.5005/jp-journals-10069-0061
\end{abstract}

\section{INTRODUCTION}

Prader-Willi syndrome (PWS), also known as the syndrome of obesity-hypomentia-hypogonadism-hypotonia, is a complex multisystem genetic disorder with a prevalence of about $1 / 10,000$ to $1 / 30,000 .^{1,2}$ It is the first known disorder of human genomic imprinting. ${ }^{3}$ The characteristic phenotype includes severe hypotonia in the neonatal period with feeding difficulty, characteristic facial features, hyperphagia, early-onset morbid obesity, short stature with short hands and feet, hypogonadism, learning disability, and other behavioral and psychiatric manifestations. ${ }^{4}$

Sleep issues are known to be common in PWS. ${ }^{1,5}$ The prevalence of obstructive sleep apnea (OSA) in children with PWS was found to be 44 to $100 \%$ in comparison with $2-3 \%$ in the normal population. ${ }^{6}$ The factors contributing to sleep-disordered breathing (SDB) in PWS include the characteristic craniofacial features, hypotonia, morbid obesity, narrowing of upper airway, and hypothalamic dysfunction. 1,2

There are currently insufficient data on sleep issues in children with PWS in India. Hence, this study was undertaken to describe the prevalence of sleep problems, polysomnography (PSG) findings, and treatment of sleep issues in Indian children with PWS.

\section{Materials and Methods}

All PSG studies and clinical history of patients attending the Pediatric Sleep Clinic at Shishuka Children's Specialty Hospital,
'Department of Pediatric Pulmonology, Shishuka Children's Specialty Hospital, Bengaluru, Karnataka, India

${ }^{2}$ Department of Pediatrics, Shishuka Children's Specialty Hospital, Bengaluru, Karnataka, India

Corresponding Author: KR Bharath Kumar Reddy, Department of Pediatric Pulmonology and Sleep, Shishuka Children's Specialty Hospital, Bengaluru, Karnataka, India, Phone number: +91 9845138419; email: drbharathreddykr@gmail.com

How to cite this article: Reddy KRBK, Nair S. A Comparative Study of Polysomnography Findings in Children with Prader-Willi Syndrome and Non-syndromic Children. Indian J Sleep Med 2020;15(4):65-68.

Source of support: Nil

Conflict of interest: None

Bengaluru, Karnataka, India, between January 2018 and March 2020 were extracted. Study subjects were divided into two groupschildren with PWS and non-syndromic children with OSA. Sleep history extracted was routinely taken by a standardized parental questionnaire prior to PSG. All children underwent PSG at one of the three attached level one sleep laboratories in Bangalore. The PSG was conducted by an on-site trained sleep technician, and its interpretation was done by a pediatric pulmonologist. Philips Respironics Alice 6 equipment was used to conduct the study with channels measuring electroencephalography (EEG), 
electrocardiography (ECG), respiratory movements (thoracic and abdominal bands), chin and leg electromyography (EMG), oxygen saturation, carbon dioxide monitoring $\left(\mathrm{EtCO}^{2}\right)$, nasal and oral airflow, microphone and video monitoring. Analysis was done using Sleepware G3 software.

Scoring and diagnosis were done as per the pediatric criteria of the American Academy of Sleep Medicine (AASM) scoring manual 2007 (updated 2018). ${ }^{7}$ OSA was categorized based on the obstructive apnea-hypopnea index $(\mathrm{OAHI})$ as mild $(\mathrm{OAHI}<1)$, moderate (OAHI 1-5), and severe $(\mathrm{OAHI}>5)$. Hypoventilation was defined as (a) an increase in $\mathrm{EtCO}^{2}$ to a value $>55 \mathrm{~mm}$ of $\mathrm{Hg}$ for $\geq 10$ minutes or (b) an increase in $\mathrm{EtCO}^{2} \geq 10 \mathrm{~mm}$ of $\mathrm{Hg}$ during sleep, to a value exceeding $50 \mathrm{~mm}$ of $\mathrm{Hg}$ for $\geq 10$ minutes.

Children with moderate-to-severe OSA were initiated on CPAP as per protocol with monitoring in the hospital for 48 hours, followed by home ventilation. Those who fulfilled criteria for hypoventilation were started on BiPAP as per the same protocol. Follow-up sleep studies were suggested to be done in 6 weeks following the initiation of CPAP or BiPAP.

\section{Statistical Analysis}

Chi-square test was used to establish significance in the prevalence of symptoms between both groups. A comparison of means between both groups for the values found on PSG was done using the $t$-test.

Ethical approval was waived by the Hospital Ethics Committee in view of the retrospective nature of the study as all the procedures being performed were part of routine diagnosis and care of children with OSA.

\section{Results}

Table 1 shows the demographic characteristics and sleep history of children with PWS compared to non-syndromic children with OSA. Both groups were matched for age and sex. All children with PWS were obese with body mass index $(\mathrm{BMI})>25$. On parental history, no significant difference was found between the two groups with respect to total sleep duration, number of nocturnal awakenings, presence of snoring, daytime somnolence, mouth breathing, choking episodes, teeth grinding, and restless legs.

All children with PWS $(n=20)$ demonstrated OSA on PSG (100\%), of which 3 (15\%) had mild, 9 (45\%) had moderate, and 8 (40\%) had severe OSA. In 22 non-syndromic children with OSA, 7 children (32\%) had mild, 9 (41\%) had moderate, and $6(27 \%)$ had severe OSA. Table 2 describes the polysomnography findings in children with PWS compared to non-syndromic children with OSA. On comparing sleep parameters, there was no significant difference between the two groups with respect to total sleep time, sleep latency, sleep efficiency, REM latency, and number of awakenings at night.

On comparing respiratory parameters, both groups showed OSA with an obstructive apnea-hypopnea index $(\mathrm{OAHI})>1$. However, the $\mathrm{OAHI}$ was significantly higher in the children with PWS $(p<0.001)$. Although, in both groups, the OAHI was more in REM compared to the NREM phase of sleep, the OAHI in REM sleep was significantly higher in children with PWS compared to non-syndromic children with OSA $(p<0.001)$. There was no such statistically significant difference seen in NREM sleep between both groups. There was a significant difference in the baseline oxygen levels $(p=0.008)$ and the total time of oxygen saturation
Table 1: Sleep history in children with PWS in comparison with nonsyndromic children with OSA

\begin{tabular}{|c|c|c|c|}
\hline & $\begin{array}{l}\text { Children } \\
\text { with PWS } \\
(n=20)\end{array}$ & $\begin{array}{l}\text { Non-syndromic } \\
\text { children with } \\
\text { OSA }(n=22)\end{array}$ & $p$-value \\
\hline $\begin{array}{l}\text { Age (in years) } \\
\quad(\text { Mean +/-SD) }\end{array}$ & $8.8( \pm 1.7)$ & $9( \pm 1.7)$ & 0.9 \\
\hline $\operatorname{Sex}(M / F)$ & $11 / 9$ & $12 / 10$ & 0.5 \\
\hline $\begin{array}{l}\text { Total sleep duration (in } \\
\text { hours) } \\
\quad \text { (Mean } \pm \text { SD) }\end{array}$ & $7.2( \pm 0.9)$ & $7.4( \pm 0.5)$ & 0.8 \\
\hline $\begin{array}{l}\text { Number of awakenings/ } \\
\text { night } \\
\quad \text { (Mean } \pm \text { SD) }\end{array}$ & $1.2( \pm 1.5)$ & $1.3( \pm 1.4)$ & 0.9 \\
\hline \multicolumn{4}{|c|}{ Presence of symptoms ( $>3$ days/week) } \\
\hline Snoring $n(\%)$ & $15 / 20(75 \%)$ & $17 / 22(77 \%)$ & 0.86 \\
\hline Daytime somnolence $n(\%)$ & $10 / 20(50 \%)$ & $8 / 22(36 \%)$ & 0.37 \\
\hline Mouth breathing $n(\%)$ & $11 / 20(55 \%)$ & $13 / 22(59 \%)$ & 0.78 \\
\hline Choking $n(\%)$ & $7 / 20(35 \%)$ & $8 / 22(36 \%)$ & 0.92 \\
\hline Teeth grinding $n(\%)$ & $4 / 20(20 \%)$ & $6 / 22(27 \%)$ & 0.58 \\
\hline Restless legs $n(\%)$ & $1 / 20(5 \%)$ & $1 / 22(4.5 \%)$ & 0.94 \\
\hline
\end{tabular}

Table 2: Polysomnography findings in children with PWS as compared to non-syndromic children with OSA

\begin{tabular}{|c|c|c|c|}
\hline & $\begin{array}{l}\text { Children } \\
\text { with PWS } \\
(n=20)\end{array}$ & $\begin{array}{l}\text { Non-syndromic } \\
\text { children with } \\
\text { OSA }(n=22)\end{array}$ & $p$-value \\
\hline \multicolumn{4}{|l|}{ Sleep parameters } \\
\hline $\begin{array}{l}\text { Total sleep time (in hours) } \\
\quad(\text { Mean } \pm \text { SD) }\end{array}$ & $6.5( \pm 0.7)$ & $6.7( \pm 0.6)$ & 0.32 \\
\hline $\begin{array}{l}\text { Sleep latency (in minutes) } \\
\quad(\text { Mean } \pm \text { SD) }\end{array}$ & $13.6( \pm 2.1)$ & $13.7( \pm 2.9)$ & 0.94 \\
\hline $\begin{array}{l}\text { Sleep efficiency }(\%) \\
\quad(\text { Mean } \pm \text { SD) }\end{array}$ & $71.6( \pm 9.0)$ & $71.7( \pm 9.0)$ & 0.99 \\
\hline $\begin{array}{l}\text { REM latency (in minutes) } \\
\quad(\text { Mean } \pm \text { SD) }\end{array}$ & $109( \pm 10.8)$ & $106.5( \pm 3.4)$ & 0.28 \\
\hline $\begin{array}{l}\text { Number of awakenings } \\
\quad(\text { Mean } \pm \text { SD) }\end{array}$ & $11( \pm 4.4)$ & $9.7( \pm 3.4)$ & 0.28 \\
\hline \multicolumn{4}{|l|}{ Respiratory parameters } \\
\hline $\begin{array}{l}\mathrm{OAHI} \\
\quad(\text { Mean } \pm \text { SD) }\end{array}$ & $12.9( \pm 5.5)$ & $8.1( \pm 2.6)$ & $<0.001$ \\
\hline $\begin{array}{l}\text { OAHI (NREM) } \\
\quad(\text { Mean } \pm \text { SD) }\end{array}$ & $2.3( \pm 1.7)$ & $1.5( \pm 0.7)$ & 0.06 \\
\hline $\begin{array}{l}\text { OAHI (REM) } \\
\quad(\text { Mean } \pm \text { SD) }\end{array}$ & $10.6( \pm 4.1)$ & $6.6( \pm 2.1)$ & $<0.001$ \\
\hline $\begin{array}{l}\text { Lowest SpO } \\
\quad(\text { Mean } \pm S D)\end{array}$ & $68.5( \pm 8.2)$ & $74.6( \pm 9.3)$ & 0.03 \\
\hline $\begin{array}{l}\text { Baseline } \mathrm{SpO}^{2} \\
\quad(\text { Mean } \pm \mathrm{SD})\end{array}$ & $91.9( \pm 1.8)$ & $93.3( \pm 1.5)$ & 0.008 \\
\hline $\begin{array}{l}\mathrm{TSaO}^{2} \\
\quad(\text { Mean } \pm \mathrm{SD})\end{array}$ & $15.9( \pm 6.7)$ & $11.3( \pm 2.9)$ & 0.005 \\
\hline
\end{tabular}

OAHI, obstructive apnea-hypopnea index; OAHI (NREM), OAHI in non-REM sleep; OAHI (REM), OAHI in REM sleep; $\mathrm{TSaO}^{2}$, percentage of time where $\mathrm{SaO}^{2}<90 \%$

below $90 \%\left(\mathrm{TSaO}^{2}\right)(p=0.005)$ between both groups, with the PWS group having lower oxygen saturation levels through the night. None of the children in both groups fulfilled criteria for hypoventilation. 
In the PWS group, 13 children who had moderate-to-severe OSA with no hypoventilation were then initiated on CPAP in the hospital. All 13 children reported resolution of nocturnal symptoms with a decrease in the number of awakenings, snoring, choking, and mouth breathing within one month of CPAP initiation. Of these 13 children on CPAP, follow-up PSG was carried out in 9 children within 6 months of initiation and NIV pressures were adjusted accordingly. All nine children demonstrated a decrease in $\mathrm{AHI}$ to normal limits with no episodes of desaturation on follow-up.

In thenon-syndromic group, out of the 15 children with moderateto-severe OSA, 10 children underwent adenotonsillectomy, 1 child who was noted to have severe OSA was initiated on CPAP therapy, and 4 were lost to follow-up. All 11 children were followed up till 6 months and reported no recurrence of sleep issues.

\section{Discussion}

Sleep-disordered breathing (SDB) is an anticipated problem in children with Prader-Willi Syndrome. ${ }^{1,2,5}$ Lin et al. reported a higher prevalence of sleep hypoxemia and sleep disruption in PWS when compared to normal subjects. ${ }^{8}$ The prevalence of OSA in patients with PWS has been reported to be 44 to $100 \%{ }^{1,9}$ in different studies. We found that all children with PWS in our study had OSA (100\%), of whom $85 \%$ had moderate-to-severe OSA. Yee et al. similarly reported a higher respiratory disturbance index (RDI) in adults with PWS compared to normal subjects. ${ }^{10}$

Obesity is a known high-risk factor for OSA in PWS. ${ }^{1,9,11}$ The upper body truncal obesity typically seen in PWS plays a major role in contributing to OSA by increasing the load on the respiratory muscles. ${ }^{9}$ All children with PWS in our study were in the obese range, which could be the main contributing factor for the higher prevalence of moderate-to-severe OSA in this group when compared to the non-syndromic group.

In our study, a significantly higher number of obstructive apneas and hypopneas were seen in the REM phase compared to the NREM phase of sleep in children with PWS. This could be attributed to a suppression of pharyngeal muscle activity known to contribute to OSA and hypoventilation in the REM phase of sleep. ${ }^{12}$ When compared to non-syndromic children with OSA, the $\mathrm{AHI}$ in REM sleep was found to be significantly higher in children with PWS. Similar observations of an increased AHI in REM sleep in PWS have been demonstrated in previous studies as well., ${ }^{4,10,11,13}$ The respiratory muscle hypotonia, upper truncal obesity, and narrowing of upper airway in sleep in children with PWS could be contributing factors for these findings. ${ }^{9,10}$ In addition to obstructive events, we also noted in our study that PWS children had a lower baseline oxygen saturation and a longer duration of hypoxemia (with saturation below 90\%) when compared to non-syndromic children with OSA. This suggests an increased need to treat the OSA as soon as possible in children with PWS.

We noted that although parents of children with PWS reported snoring (75\%) and mouth breathing (55\%), there was no significant difference in the history when compared to non-syndromic children with OSA. However, on the polysomnography findings of both groups, it was clear that children with PWS had a more severe OSA than the non-syndromic childrenSuch a discrepancy between the history of sleep problems and PSG findings has been observed in previous studies as well..$^{9-11,14}$ Parents underestimate the true severity of the obstructive symptoms experienced by children with PWS, reiterating the need to conduct PSG in all children with PWS routinely.
Children with PWS are known to suffer from narcolepsy-like symptoms with daytime somnolence. ${ }^{9,11}$ Although $50 \%$ of children with PWS in our study presented with daytime somnolence, the sleep latency was found to be within normal limits. Sleep latency is known to be decreased in narcolepsy, necessitating the need for a multiple sleep latency test (MSLT) in these specific children. MSLT was not conducted in any of the children with PWS in our study due to the lack of any other features supportive of a diagnosis of narcolepsy. There was also an improvement in both the night symptoms and daytime somnolence in children with PWS initiated on CPAP in our study. Hence, the daytime somnolence in these children could be a result of poor sleep efficiency and multiple awakenings than narcolepsy.

In the year 2000, the FDA approved the use of human growth hormone (hGH) in children with PWS to help with the improvement of linear growth, fat utilization, bone mineral density, muscle mass and a decrease in total body fat and respiratory muscle hypotonia. ${ }^{4,15}$ However, a worsening of OSA and few fatalities were reported in the initial months of starting hGH therapy in children who were morbidly obese or had chronic respiratory inflammation. ${ }^{4,16}$ Thus, subsequent guidelines necessitated the need for PSG, initiation of NIV, treatment of OSA, and a follow-up PSG prior to initiation of growth hormone therapy in children with PWS. ${ }^{16}$ Nine children in our study with moderate-to-severe OSA who underwent a follow-up PSG showed a good response to NIV and could safely be started on growth hormone, if needed without worsening of OSA.

\section{Conclusion}

In conclusion, children with PWS need to undergo a routine polysomnography to estimate the extent of OSA, which is an extremely common entity in this group. A PSG aids in the diagnosis and treatment of OSA, followed by titration of NIV on a follow-up PSG, prior to the initiation of growth hormone therapy in children with PWS.

\section{Clinical Significance}

The degree of obstruction could be underestimated on parental history in children with PWS, thus necessitating the need for a PSG in all children with PWS, especially prior to hGH therapy.

\section{ACKnOWLedgments}

This study has not received any funding from any source.

\section{References}

1. Sedky K, Bennett DS, Pumariega A. Prader Willi syndrome and obstructive sleep apnea: co-occurrence in the pediatric population. J Clin Sleep Med 2014;10(4):403-409. DOI: 10.5664/jcsm.3616.

2. Gillett ES, Perez IA. Disorders of sleep and ventilatory control in Prader-Willi syndrome. Diseases 2016;4(3):23. DOI: 10.3390/ diseases4030023.

3. Butler MG. Genomic imprinting disorders in humans: a mini-review. J Assist Reprod Genet 2009;26(9-10):477-486. DOI: 10.1007/s10815009-9353-3.

4. Miller J, Silverstein J, Shuster J, et al. Short-term effects of growth hormone on sleep abnormalities in Prader-Willi syndrome. J Clin Endocrinol Metab 2006;91(2):413-417. DOI: 10.1210/jc.2005-1279.

5. Pavone M, Caldarelli V, Khirani S, et al. Sleep disordered breathing in patients with Prader-Willi syndrome: a multicenter study. Pediatr Pulmonol 2015;50(12):1354-1359. DOI: 10.1002/ppul.23177. 
6. Capdevila OS, Kheirandish-Gozal L, Dayyat E, et al. Pediatric obstructive sleep apnea: complications, management, and longterm outcomes. Proc Am Thorac Soc 2008;5(2):274-282. DOI: 10.1513/ pats.200708-138MG.

7. Iber C, Ancoli-Israel S, Chesson A, et al. The AASM Manual for the Scoring of Sleep and Associated Events: Rules, Terminology and Technical Specifications, 1st ed. Westchester, IL: American Academy of Sleep Medicine; 2007.

8. Lin HY, Lin SP, Lin CC, et al. Polysomnographic characteristics in patients with Prader-Willi syndrome. Pediatr Pulmonol 2007;42(10):881-887. DOI: 10.1002/ppul.20673.

9. Hertz G, Cataletto M, Feinsilver $\mathrm{SH}$, et al. Sleep and breathing patterns in patients with Prader Willi Syndrome (PWS): effects of age and gender. Sleep 1993;16(4):366-371. DOI: 10.1093/sleep/16.4.366.

10. Yee BJ, Buchanan PR, Mahadev S, et al. Assessment of sleep and breathing in adults with Prader-Willi syndrome: a case control series. J Clin Sleep Med 2007;3(7):713-718. DOI: 10.5664/jcsm.27028.

11. Clift S, Dahlitz M, Parkes JD. Sleep apnoea in the Prader-Willi syndrome. J Sleep Res 1994;3(2):121-126. DOI: 10.1111/j.1365-2869. 1994.tb00115.x.
12. Grace KP, Hughes SW, Horner RL. Identification of the mechanism mediating genioglossus muscle suppression in REM sleep. Am J Respir Crit Care Med 2013;187(3):311-319. DOI: 10.1164/rccm.20120916540C.

13. Polytarchou A, Katsouli G, Tsaoussoglou M, et al. Obstructive events in children with Prader-Willi syndrome occur predominantly during rapid eye movement sleep. Sleep Med 2019;54:43-47. DOI: 10.1016/j. sleep.2018.09.026.

14. Williams K, Scheimann A, Sutton V, et al. Sleepiness and sleep disordered breathing in Prader-Willi syndrome: relationship to genotype, growth hormone therapy, and body composition. J Clin Sleep Med 2008;4(2):111-118. DOI: 10.5664/jcsm.27126.

15. Irizarry KA, Miller $M$, Freemark $M$, et al. Prader Willi syndrome: genetics, metabolomics, hormonal function, and new approaches to therapy. Adv Pediatr 2016;63(1):47-77. DOI: 10.1016/j. yapd.2016.04.005.

16. Eiholzer U. Deaths in children with Prader-Willi syndrome. A contribution to the debate about the safety of growth hormone treatment in children with PWS. Horm Res 2005;63(1):33-39. DOI: $10.1159 / 000082745$. 